\title{
Membrane localization and topology of the Yersinia pestis YscJ lipoprotein
}

\author{
Eugenia Silva-Herzog, Franco Ferracci, Michael W. Jackson, \\ Sabrina S. Joseph and Gregory V. Plano
}

Correspondence
Gregory V. Plano
gplano@med.miami.edu

Received 7 September 2007

Revised 7 November 2007

Accepted 9 November 2007

\author{
Department of Microbiology and Immunology, University of Miami Miller School of Medicine, \\ Miami, FL 33101, USA
}

\section{INTRODUCTION}

Bacterial pathogens are responsible for numerous diseases in higher plants, insects and animals. Some Gram-negative bacterial pathogens use type III secretion systems (T3SSs) to modulate eukaryotic cell function to their advantage (Hueck, 1998). T3SSs function to transport effector proteins from the cytoplasmic compartment of a bacterial cell directly into a targeted eukaryotic cell (Rosqvist et al., 1994). These systems are essential for the virulence of many pathogens; however, T3SSs have also been identified in bacterial symbionts of both plants and insects (Troisfontaines \& Cornelis, 2005). In addition, the T3S process has been demonstrated to play a critical role in the assembly of the bacterial flagellum (Macnab, 1999). Although the proteins secreted by the different T3SSs are highly divergent, the core components of the secretion apparatus and the mechanism of secretion appear to be conserved (Pallen et al., 2005).

The human pathogenic yersiniae (Yersinia enterocolitica, $Y$. pseudotuberculosis and $Y$. pestis) utilize a virulenceplasmid-encoded T3SS to deliver effector proteins that disrupt host cell signalling pathways involved in bacterial

Abbreviations: IM, inner membrane; NC, needle complex; OM, outer membrane; T3S, type III secretion; T3SS, type III secretion system; TBA, tryptose blood agar; TM, transmembrane; Ysc, Yersinia secretion.

Supplementary tables of strains, plasmids and primers are available with the online version of this paper. phagocytosis and in the production of proinflammatory cytokines (Juris et al., 2002; Viboud \& Bliska, 2005). These capabilities allow the yersiniae to avoid the host's innate defences and to multiply within the host's tissues. The Yersinia T3S apparatus is composed of 21 essential Yersinia secretion (Ysc) proteins that are predicted to assemble into a large secretory complex that spans both bacterial membranes (Cornelis, 2002; Yip \& Strynadka, 2006). At least 11 components of this macromolecular complex are conserved in essentially all virulence-associated, as well as flagellar, T3SSs, suggesting a common core structure.

A portion of the T3S apparatus, or injectisome, of several bacterial pathogens has been isolated and visualized by transmission electron microscopy (Blocker et al., 1999; Kubori et al., 1998; Sekiya et al., 2001). The isolated structure, termed the needle complex (NC), consists of a base structure that spans both bacterial membranes and a thin needle-like structure that extends beyond the surface of the bacterium. Not surprisingly, the NC base structure closely resembles the related flagellar basal body structure (Kubori et al., 1998).

The assembly of the T3S apparatus, like that of the flagellar system, initiates with a sec-dependent stage that includes localization and oligomerization of members of the $\mathrm{YscC} /$ InvG, YscD/PrgH and YscJ/PrgK families (Kimbrough \& Miller, 2000). In Salmonella enterica, the PrgH and PrgK proteins have been shown to form the base of the NC structure (Marlovits et al., 2004). The Yersinia YscD and 
YscJ proteins are hypothesized to form a similar base structure. The YscJ/PrgK family of proteins is highly conserved in all virulence-related T3SSs (Allaoui et al., 1992). Members of this family also share homology with the N-terminal region of FliF, the flagellar membrane/ supramembrane (MS)-ring protein (Hueck, 1998; Ueno et al., 1994). The Yersinia YscD and Salmonella PrgH proteins share significant primary amino-acid sequence identity (Pallen et al., 2005) and have both been shown to be associated with the inner membrane (IM) (Kimbrough \& Miller, 2000; Plano \& Straley, 1995). YscC and InvG are members of the secretin family and have been shown to form ring-shaped structures in the bacterial outer membrane (OM) (Crago \& Koronakis, 1998; Koster et al., 1997). Stable expression, OM localization and oligomerization of $\mathrm{YscC}$ requires a lipoprotein chaperone, termed YscW, and the insertion of two DsbA-dependent disulfide bonds in the C-terminal region of the protein (Burghout et al., 2004; Jackson \& Plano, 1999; Koster et al., 1997).

All YscJ/PrgK family members have a sec-dependent signal sequence with a consensus lipoprotein signal peptidase recognition/cleavage site and, with the exception of EscJ, a predicted C-terminal hydrophobic IM-spanning domain. The predicted C-terminal transmembrane (TM) domain of YscJ is immediately followed by an Arg-Lys-Lys sequence that may serve as a stop transfer signal. Yip et al. (2005) have provided evidence that EscJ forms a large 24-subunit 'doughnut-shaped' platform that may be anchored to the periplasmic face of the IM by its $\mathrm{N}$-terminal acyl groups. In contrast, Crepin et al. (2005) found that EscJ was predominantly localized to the OM. Analysis of the $17 \AA$ structure of the S. enterica SPI-1 NC suggests that PrgK and $\mathrm{PrgH}$ are both associated with the bacterial IM (Marlovits et al., 2004). Thus, YscJ family members are probably IM lipoproteins that form the base of the T3S apparatus, probably serving both as a platform for the assembly of the T3S apparatus and as part of the structural link between the IM and OM components of this apparatus.

Bacterial lipoproteins are initially synthesized as precursors in the cytoplasm that can be translocated across the IM by the Sec translocation machinery (Hayashi \& $\mathrm{Wu}, 1990$ ). Subsequent processing to mature lipoproteins occurs on the periplasmic side of the IM. A consensus sequence ( $\mathrm{L}-\mathrm{A} /$ S-G/A ${ }^{\downarrow} \mathrm{C}$ ), termed the lipo-box, targets lipoprotein precursors for modification and subsequent cleavage $\left({ }^{\downarrow}\right)$. The cysteine $(+1$ residue of the mature lipoprotein) is initially modified through the addition of a diacylglycerol molecule to its thiol group. This modification allows cleavage by the prolipoprotein signal peptidase (Tokunaga et al., 1982). A third acyl chain is then added to the amino group of the modified $\mathrm{N}$-terminal cysteine residue by apolipoprotein $\mathrm{N}$ acyltransferase. Acylated lipoproteins are found anchored to the periplasmic leaflet of either the IM or the OM.

The machinery that transports lipoproteins to the OM has been extensively studied in Escherichia coli. An Asp at position +2 acts as an IM retention signal (Terada et al.,
2001; Yamaguchi et al., 1988), whereas essentially all other residues in the +2 position allow lipoprotein transport to the OM via the Lol machinery (Tokuda \& Matsuyama, 2004). The Lol transport machinery consists of the LolABCD and E proteins. The LolCDE complex is an IM $\mathrm{ABC}$ transporter that recognizes and delivers fully acylated mature lipoproteins to a periplasmic chaperone termed LolA (Matsuyama et al., 1995; Yakushi et al., 2000). The LolA-lipoprotein complex traverses the periplasmic space and delivers the lipoprotein to LolB, an OM receptor protein (Matsuyama et al., 1997). The IM retention signal (Asp in the +2 position) functions as a Lol avoidance signal and prevents the recognition of lipoproteins by LolCDE, leaving the lipoprotein in the IM (Hara et al., 2003). Recent studies have revealed that the IM retention of lipoproteins can also be influenced by the residues in positions +3 and +4 , as well as by structural constraints of the polypeptide (Masuda et al., 2002; Robichon et al., 2003; Terada et al., 2001). Interestingly, the HrcJ lipoprotein, a YscJ/PrgK family member, has an Asp residue in position +2 ; however, most YscJ/PrgK family members, including EscJ, YscJ, PrgK, PscJ, LscJ and RhoJ, have a Lys or another residue in position +2 (see Fig. 1b), suggesting that localization of YscJ/PrgK family members may occur by a unique mechanism.

In this study, we determined the topology of YscJ and have shown that periplasmic YscJ is inserted in the IM both via its lipid moiety and via a C-terminal TM domain. Localization of YscJ to the IM occurred regardless of the amino acid residues in the +2 or +3 position. Furthermore, we provide evidence that the IM localization of the YscJ lipoprotein moiety is dictated by an N-terminal domain that may function to prevent YscJ $\mathrm{N}$-acylation.

\section{METHODS}

Bacterial strains and growth conditions. Bacterial strains and plasmids used in this study are described in detail in Supplementary Table S1, available with the online version of this paper. All Y. pestis KIM strains are $\mathrm{Pgm}^{-}$and avirulent from peripheral routes of infection (Une \& Brubaker, 1984). These strains and their derivatives were routinely grown in heart infusion broth (HIB) or on tryptose blood agar (TBA) base plates (Difco). For Yop secretion experiments, $Y$. pestis strains were grown in the presence or absence of $2.5 \mathrm{mM}$ calcium chloride in the defined medium TMH (Goguen et al., 1984). E. coli SY327 $\lambda$ pir (Miller \& Mekalanos, 1988) was used as a host strain for derivatives of the suicide vector pUK4134 (Skrzypek et al., 1993). E. coli XL1 Blue (Stratagene) or DH5 $\alpha$ (Cambau et al., 1993) was used for routine cloning experiments, and E. coli BL21(DE3) (Novagen) for overexpression of polyhistidine-tagged YscJ.

Construction of a ysc J deletion mutant. A $\sim 2.9 \mathrm{~kb}$ BamHI-ClaI fragment of plasmid pPH2 (Haddix \& Straley, 1992), encoding yscGHIJKL (Fig. 1a), was inserted into BamHI- and ClaI-digested pBluescript SK ${ }^{-}$(Stratagene), generating plasmid pYscHIJKL. Unique StuI and EcoRV sites flanking the region encoding amino acids 44-94 of YscJ were used to create an in-frame deletion within $y s c J . A \sim 3.9 \mathrm{~kb}$ Ecl136II-ScaI fragment, carrying the $y s c J$ deletion, was inserted into the EcoRV site of pUK4134, creating plasmid pUK4134.P26. This construct was utilized to move the $y s c J$ deletion into plasmid pCD1 of 


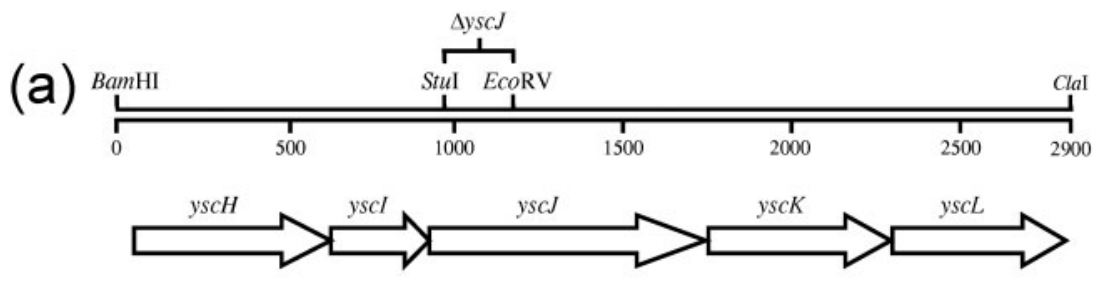

(b)

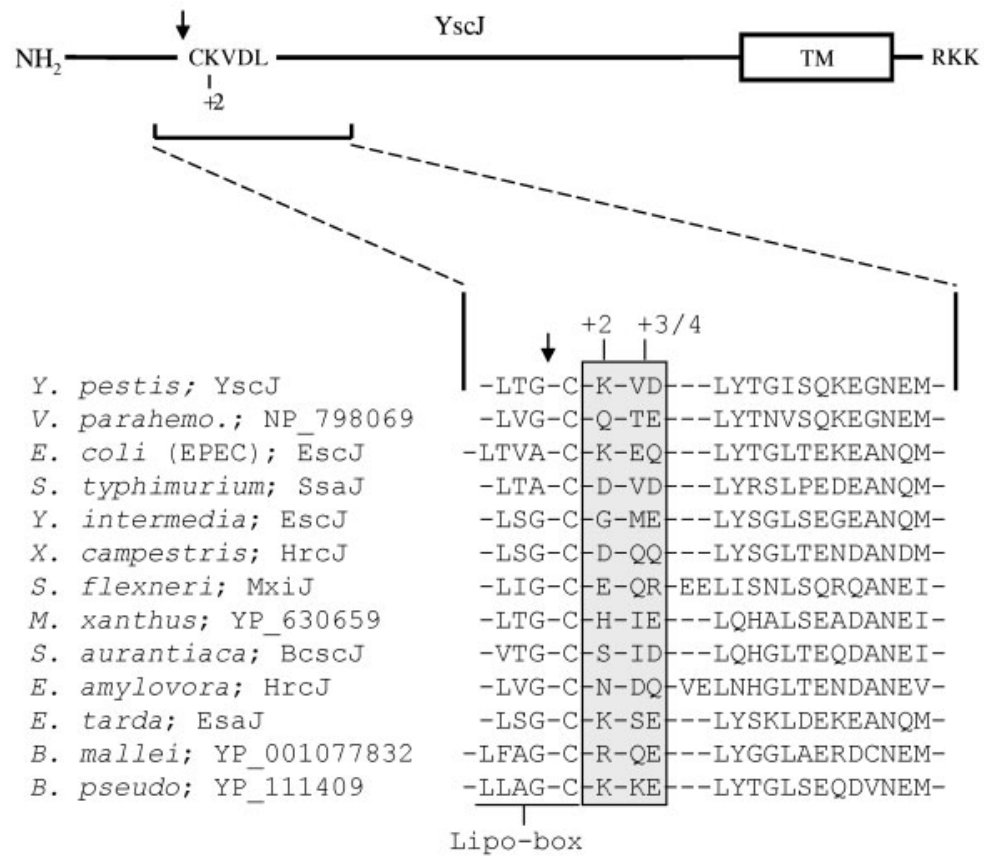

Fig. 1. The $y s c J$ gene encodes a lipoprotein. (a) Genetic map of the $y s c H I J K L$ region of plasmid pCD1. Stul and EcoRV sites were used to create an in-frame deletion in yscJ. (b) Model of the YscJ presecretory protein. The YscJ $\mathrm{N}$-terminal secretion signal contains a consensus prolipoprotein signal peptidase recognition/cleavage site $\left(\mathrm{LTG}^{\downarrow} \mathrm{C}\right)$. An amino-acid sequence alignment (YscJ residues -3 to +17 ) of various YscJ/PrgK family members is presented, which shows the diversity of amino-acid residues found in the $+2,+3$ and +4 positions. The predicted prolipoprotein signal peptidase cleavage site is shown by the arrow.
Y. pestis KIM8-3002 as previously described (Skrzypek et al., 1993), generating $Y$. pestis KIM8-3002.P26.

Construction of a ysc $\mathbf{C}$ yscW deletion mutant. A $\sim 4.6 \mathrm{~kb}$ BamHI fragment of pCD1 (BamHI G fragment), containing the $y s c W$ gene, was inserted into plasmid pT7Blue (Novagen), generating plasmid pT7-YscW. Unique BlpI sites flanking sequences encoding YscW amino-acid residues 24 to 102 were used to create an in-frame deletion within $y s c W$. A $\sim 4.2 \mathrm{~kb}$ Ecl136II-EcoRV fragment, carrying the $y s c W$ deletion, was inserted into the EcoRV site of pUK4134, creating plasmid pUK4134.P86. Plasmid pUK4134.P86 was utilized to move the $y s c W$ deletion into plasmid pCD1 of Y. pestis KIM5-3001.12 $(\Delta y s c C)$, generating $Y$. pestis KIM5-3001.P86 ( $\Delta y s c W \quad \Delta y s c C)$. Transformation of this strain with plasmid pLG-YscC generated a strain specifically deficient in expression of YscW.

Construction of YscJ expression plasmids. Plasmid pYscJ was constructed by inserting an 807 bp PCR-amplified fragment carrying the entire $y s c J$ gene into Ecl136II/BamHI-digested pBluescript $\mathrm{SK}^{-}$ (Stratagene), such that the $y s c J$ gene was transcribed from the vector lac promoter. Oligonucleotide primers YscJ1 and YscJ2 were used to amplify the $y s c J$-encoding fragment. Oligonucleotides used in this study are presented in Supplementary Table S2, available with the online version of this paper. Plasmid pYscJ was used in complementation experiments.

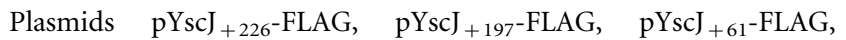
$\mathrm{pYsc}_{+42}$-FLAG and $\mathrm{pYscJ}_{+25}$-FLAG express the N-terminal +226 , $+198,+61,+42$ or +25 amino-acid residues of the mature YscJ protein with a C-terminal FLAG epitope tag. DNA fragments amplified with oligonucleotide primers YscJ-FLAG1 and YscJ-226, YscJ-197, YscJ-61, YscJ-42 or YscJ-25 were inserted into HindIII- and Sall-digested plasmid pFLAG-CTC (Sigma).

Plasmids pCDD-YscJ, pPal-CSS-YscJ, pDsbA-YscJ were constructed using the PCR-ligation-PCR technique (Ali \& Steinkasserer, 1995). Internal oligonucleotide primers Pal-1, CDD-1 and DsbA-1 were used in conjunction with outside primer YscJ-KpnI; primers Pal-2, CDD-2 and DsbA-2 were paired with outside primer YscJ-HindIII. The corresponding Pal, CDD and DsbA PCR fragments were ligated to each other and the resultant full-length fragment was amplified using primers YscJ-KpnI and YscJ-HindIII. The analogous wild-type YscJ fragment was also generated using primers YscJ-KpnI and YscJHindIII, with plasmid pCD1 as template. The amplified fragments were digested with KpnI and HindIII and inserted into KpnI- and HindIII-digested pBAD30 (Guzman et al., 1995), generating plasmids pYscJ3, pCDD-YscJ, pPal-CSS-YscJ and pDsbA-YscJ. DNA fragments inserted in plasmids $\mathrm{pYscJ} 3_{+61}, \mathrm{pCDD}-\mathrm{Ysc}_{+61}$ or pPAL-CSS$\mathrm{YscJ}_{+61}$ were generated with primers YscJ-KpnI and $\mathrm{YscJ}_{+61^{-}}$ HindIII using plasmids pYscJ3, pCDD-YscJ and pPal-CSS-YscJ, respectively, as template. The resulting PCR fragments were digested 
and inserted into pBAD30, generating plasmids pYscJ3 $3_{+61}$, pCDD$\mathrm{YscJ}_{+61}$ and pPAL-CSS-YscJ +61 .

Construction of plasmids encoding YscJ-YscW hybrid pro-

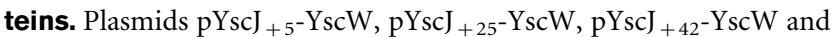
pYscJ $_{+61}$-YscW were constructed by the PCR-ligation-PCR technique (Ali \& Steinkasserer, 1995). Internal oligonucleotide primers $\mathrm{YscJ}_{+5}$, $\mathrm{YscJ}_{+25}, \mathrm{YscJ}_{+42}, \mathrm{YscJ}_{+61}$ were paired with outside primer YscJ-KpnI. Internal oligonucleotide primer $\mathrm{YscW}_{+1}$ was paired with primer YscW-XbaI. The resultant $\mathrm{YscJ}_{+5}, \mathrm{YscJ}_{+25}, \mathrm{YscJ}_{+42}$ and $\mathrm{YscJ}_{+61} \mathrm{PCR}$ fragments were individually ligated to the $\mathrm{YscW}_{+1}$ PCR fragment and the resultant full-length fragments were amplified using primers YscJ$K p n I$ and YscW-XbaI. The DNA insert in plasmid pYscW was generated using primers YscW-KpnI and YscW-XbaI. The amplified fragments were digested with $K p n \mathrm{I}$ and $\mathrm{Xba \textrm {I }}$ and inserted into KpnIand XbaI-digested pBAD30 (Guzman et al., 1995), generating plasmids pYscW, pYscJ $+5-\mathrm{YscW}_{2}, \mathrm{pYscJ}_{+25}-\mathrm{YscW}_{2}, \mathrm{pYscJ}_{+42}-\mathrm{YscW}$ and $\mathrm{pYscJ}_{+61}-\mathrm{YscW}$.

Construction of plasmids $\mathrm{pYscV}_{\mathrm{TM} 1}-\mathrm{YscJ}_{\mathrm{SC}}$ and $\mathrm{pYscJ-} \mathbf{Y s C V}_{\mathrm{TM} 2}$. Plasmid $\mathrm{pYscV}_{\mathrm{TM} 1}-\mathrm{YscJ}$ encodes a $\mathrm{YscV}-\mathrm{Ysc}$ hybrid protein consisting of residues 1-40 of YscV (TM 1 of YscV) fused to residues +2 to +226 of YscJ. The $y s c V-y s c J$ gene fusion was constructed by the PCRligation-PCR technique (Ali \& Steinkasserer, 1995). Primers YscV$\mathrm{XbaI}$ and $\mathrm{YscV}-2$ were used to amplify a $y s c V$ fragment that carries upstream sequences including the $y s c V$ ribosome-binding site as well as the coding region for amino acids $1-40$ of $\mathrm{YscV}$. Primers $\mathrm{YscJ}_{+2}-\mathrm{F}$ and YscJ-HindIII were used to amplify the $y s c J$ fragment encoding residues +2 to +226 of YscJ. The resultant YscV- and YscJ-encoding fragments were ligated and the gene fusion amplified with primers YscV-XbaI and YscJ-HindIII. The resulting DNA fragment was digested with $\mathrm{XbaI}$ and HindIII and inserted into XbaI- and HindIIIdigested $\mathrm{pBAD} 30$, generating plasmid $\mathrm{pYscV}_{\mathrm{TM} 1}-\mathrm{YscJ}$.

Plasmid pYscJ-YscV $\mathrm{TM}_{\mathrm{TM}}$ encodes a mature $\mathrm{YscJ}-\mathrm{YscV}$ hybrid lipoprotein consisting of YscJ residues +1 to +199 fused to residues 42 to 61 of $\mathrm{YscV}$ (TM 2 of $\mathrm{YscV}$ ) terminating with the C-terminal four residues of YscJ (QRKK). The $y s c J-y s c V$ gene fusion was constructed by the PCR-ligation-PCR technique (Ali \& Steinkasserer, 1995). Primers YscJ-XbaI and $\mathrm{YscJ}_{+199}$ were used to amplify a $y s c J$ fragment that encodes the secretion signal and residues +1 to +199 of YscJ. Primers YscV-TM2 and YscV-QRKK-HindIII were used to amplify the $y s c V$ fragment encoding residues $42-61$ of $\mathrm{YscV}$ with a C-terminal QRKK sequence. The resultant YscJ- and $\mathrm{YscV}$-encoding fragments were ligated and the gene fusion amplified with primers YscJ-XbaI and YscV-QRKK-HindIII. The resulting DNA fragment was digested with $\mathrm{XbaI}$ and HindIII and inserted into XbaI- and HindIII-digested pBAD30, generating plasmid pYscJ-YscV $\mathrm{TM}_{\mathrm{TM}}$.

Construction of plasmid pLG-YscC. A $\sim 2.3 \mathrm{~kb}$ YscC-encoding fragment was obtained by $P v u I I$ and $X m n I$ digestion of plasmid pYscC1 (Plano \& Straley, 1995). The YscC-encoding fragment was inserted into HincII-digested pLG338 (Stoker et al., 1982), generating plasmid pLG-YscC.

Construction of $y s c J:$ : phoAlacZ $\alpha$ fusions. The dual phoAlacZ $\alpha$ gene fusion reporter system developed by Alexeyev \& Winkler (1999) was used to investigate the membrane topology of YscJ in $Y$. pestis. A SacI-NarI fragment of plasmid pMA632 (Alexeyev \& Winkler, 1999), encoding the mature portion of the E. coli alkaline phosphatase protein and the $\alpha$ peptide fragment of E. coli $\beta$-galactosidase, was inserted into SacI- and ClaI-digested pBluescript $\mathrm{SK}^{-}$, generating plasmid pPHO1. DNA fragments encoding YscJ amino-acids residues +1 to $+131,+1$ to $+198,+1$ to +221 and +1 to +226 of YscJ were generated by PCR with a plasmid pYscJ-specific T3 oligonucleotide primer and primers J131, J198, J221 and J226, respectively. The J131, J198, J221 and J226 primers were tailed with an ApaI site. After digestion with SacI and ApaI, the PCR fragments were inserted inframe with the phoAlacZ $\alpha$ gene fusion of $\mathrm{pPHO} 1$, generating plasmids $\mathrm{pPHO}^{-Y_{s c J}+131}, \quad \mathrm{pPHO}-\mathrm{YscJ}_{+198}, \quad \mathrm{pPHO}-\mathrm{Ysc}_{+221}$ and pPHO$\mathrm{YscJ}_{+226}$. Reporter plasmids were electroporated into the Y. pestis $y s c J$ deletion mutant for the determination of alkaline phosphatase activity. Alkaline phosphatase activity was measured by determining the rate of $p$-nitrophenyl phosphate hydrolysis in permeabilized cells as previously described (Plano et al., 1991).

Generation of antiserum specific for YscJ. Overexpression and purification of polyhistidine-tagged YscJ was facilitated by construction of expression plasmid pET-YscJ1. The entire yscJ gene was amplified by PCR using oligonucleotide primers YscJ-H1 and YscJ$\mathrm{H} 2$. The oligonucleotides were tailed with $\mathrm{NdeI}$ and Bam HI sites to facilitate insertion of the amplified fragment into the NdeI- and BamHI-digested pET15b (Novagen). Plasmid pET-YscJ1 was electroporated into E. coli BL21(DE3) for overexpression of polyhistidinetagged YscJ. Purification of the polyhistidine-tagged protein was performed according to the manufacturer's protocol with the HisBind Resin and Buffer kit (Novagen). Purified YscJ protein was used to raise antiserum specific for YscJ in female New Zealand White rabbits (Animal Pharm Services).

Expression and purification of full-length YscJ-6x-His for $\mathbf{N}$ terminal sequence analysis. Plasmid pYscJ-6x-His was constructed by amplifying a $y s c J$-encoding fragment of pCD1 with primers YscJ$K p n \mathrm{I}$ and YscJ-6x-His-XbaI. The YscJ-6x-His-XbaI oligonucleotide provides the coding sequence for six histidine residues and a stop codon followed by an XbaI site. The resulting fragment was digested with $K p n \mathrm{I}$ and $X b a \mathrm{I}$ and inserted into KpnI- and $\mathrm{XbaI}$-digested pBAD30, generating plasmid pYscJ-6x-His. Plasmid pYscJ-6x-His was moved into $Y$. pestis KIM10 (no T3SS). The resulting strain was grown in $250 \mathrm{ml} \mathrm{HIB}$ to $\mathrm{OD}_{620} 0.5$. The expression of the YscJ-6x-His protein was induced by the addition of $0.2 \%(\mathrm{w} / \mathrm{v}) \mathrm{L}$-arabinose for $3 \mathrm{~h}$. Chloramphenicol $\left(20 \mu \mathrm{g} \mathrm{ml}^{-1}\right)$ was added $1 \mathrm{~h}$ prior to harvest to halt protein synthesis and to allow the processing of the YscJ-6x-His protein to be completed. The bacteria were harvested, and lysed by two passages through a French pressure cell. The lysates were then centrifuged at $8000 \mathrm{~g}$ at $4{ }^{\circ} \mathrm{C}$ for $10 \mathrm{~min}$ twice to remove large debris and unlysed cells. The resultant supernatant was subjected to ultracentrifugation at $160000 \mathrm{~g}$ for $1 \mathrm{~h}$ at $4{ }^{\circ} \mathrm{C}$ to pellet the total membrane fraction. The recovered membranes were solubilized with $50 \mathrm{mM}$ Tris/HCl, pH 7.4 containing $0.1 \%(\mathrm{w} / \mathrm{v})$ SDS and $1 \%(\mathrm{v} / \mathrm{v})$ $\mathrm{NP}-40$. Insoluble material was pelleted by ultracentrifugation and the solubilized YscJ-6x-His was purified according to the manufacturer's protocol with Nickel Sepharose 6 Fast Flow resin (Amersham Bioscience). The purified YscJ-6x-His protein was analysed by SDSPAGE, transferred to BioTrace PVDF membranes (Pall Life Sciences) and $\mathrm{N}$-terminal sequence analysis of the processed YscJ-6x-His protein was performed by the Protein Core Facility at Columbia University.

SDS-PAGE and immunoblotting. Volumes of cellular fractions corresponding to equal numbers of bacteria or equal amounts of protein were mixed $1: 1(\mathrm{v} / \mathrm{v})$ with $2 \times$ electrophoresis sample buffer and analysed by SDS-PAGE and immunoblotting essentially as described by Plano et al. (1991). Y. pestis proteins were visualized as previously described, using antibodies specific for YopE, YopM, YopN, YscV, YscC, YscW or YscJ. FLAG-tagged proteins were detected using anti-FLAG polyclonal antibody (Sigma).

Membrane fractionation. Separation of $Y$. pestis IM and OM fractions was performed by flotation sucrose density-gradient centrifugation following a modification of the procedure reported by Robichon et al. (2005). Briefly, Y. pestis cultures were grown at $27{ }^{\circ} \mathrm{C}$ for $1-2 \mathrm{~h}$ and then shifted to $37^{\circ} \mathrm{C}$ for $3-4 \mathrm{~h}$. Y. pestis strains carrying pBAD 30 constructs were induced by the addition of $0.2 \%$ 
(w/v) L-arabinose and pFLAG constructs with $0.1 \mathrm{mM}$ IPTG. Bacterial cultures were harvested by centrifugation, resuspended in $25 \mathrm{mM}$ HEPES, $5 \mathrm{mM}$ EDTA, pH 7.4 (HE buffer) and disrupted by two passages through a French pressure cell. DNase I and RNase A were added to the lysate to degrade released DNA and RNA. The lysates were then centrifuged at $8000 \mathrm{~g}$ at $4{ }^{\circ} \mathrm{C}$ for $10 \mathrm{~min}$ twice to remove large debris and unlysed cells. The membranes were collected by ultracentrifugation at $160000 \mathrm{~g}$ at $4{ }^{\circ} \mathrm{C}$ for $1 \mathrm{~h}$ and resuspended in $60 \%(\mathrm{w} / \mathrm{w})$ sucrose, in HE buffer. Membranes were placed at the bottom of gradients created by steps of $56 \%, 53 \%, 50 \%, 47 \%, 44 \%$, $41 \%, 38 \%$ and $35 \%(\mathrm{w} / \mathrm{w})$ sucrose solutions. The gradients were centrifuged in swinging-bucket rotors at $220000 \mathrm{~g}$ for $36 \mathrm{~h}$. Fractions were collected from the top of the tubes and centrifuged at $160000 \mathrm{~g}$ at $4{ }^{\circ} \mathrm{C}$ for $1 \mathrm{~h}$ after dilution of the sucrose to less than $6 \%(\mathrm{w} / \mathrm{w})$. Membrane pellets were resuspended in HE buffer and analysed by SDS-PAGE and immunoblotting.

\section{RESULTS}

\section{Secretion phenotype of the yscJ deletion mutant}

Secretion of YopE by the parent strain Y. pestis KIM8-3002, the $y s c J$ deletion mutant KIM8-3002.P26, and the yscJ deletion mutant carrying plasmid pYscJ, $\mathrm{pYscJ}_{+226^{-}}$FLAG or $\mathrm{pYscJ}_{+197}$-FLAG was analysed by SDS-PAGE and immunoblotting (Fig. 2a). Plasmid pYscJ encodes the full-length YscJ protein (Fig. 2b). Plasmids $\mathrm{pYscJ}_{+226^{-}}$ FLAG and pYscJ $_{+197}$-FLAG encode full-length and truncated FLAG epitope-tagged versions of YscJ, respectively. The YscJ +197 -FLAG protein lacks the C-terminal TM region and predicted RKK stop-transfer sequence. The yscJ deletion strain failed to secrete YopE at $37{ }^{\circ} \mathrm{C}$ in the presence or absence of calcium, whereas the parent strain, as well as the strain transformed with pYscJ or $\mathrm{pYsc}_{+226^{-}}$ FLAG, showed normal calcium-regulated secretion of YopE. These data confirm that the lack of Yop secretion by the $y s c J$ deletion mutant was due to the absence of the YscJ protein and not to polar effects on downstream genes. Moreover, the addition of a FLAG epitope to the Cterminus of YscJ did not prevent the assembly of a functional T3SS. In contrast, expression of the $\mathrm{YscJ}_{+197^{-}}$ FLAG protein, which lacks the C-terminal TM domain, failed to restore YopE secretion, indicating that this region is essential for YscJ expression, stability or function.

Polyclonal antiserum raised against a polyhistidine-tagged YscJ protein was used to identify the $y s c J$ gene product in immunoblots from cell-pellet fractions of the parent strain, the yscJ deletion mutant and the deletion mutant transformed with plasmids pYscJ, pYscJ +226 -FLAG or pYscJ $_{+197}$-FLAG (Fig. 2a). The $y s c J$ locus is predicted to encode a mature 226 amino acid lipoprotein with a predicted molecular mass of approximately $25 \mathrm{kDa}$ (Allaoui et al., 1995). A protein with an apparent molecular mass of $25 \mathrm{kDa}$ was observed in the parent strain and in

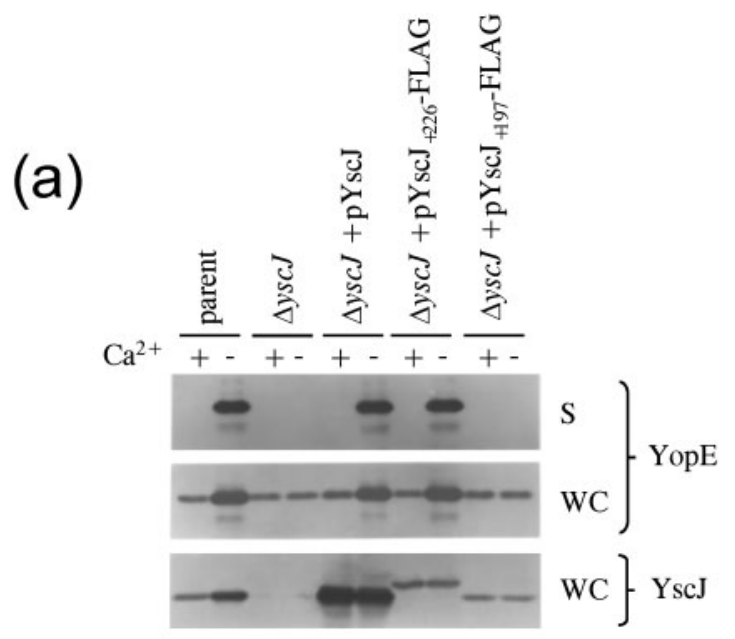

(b)

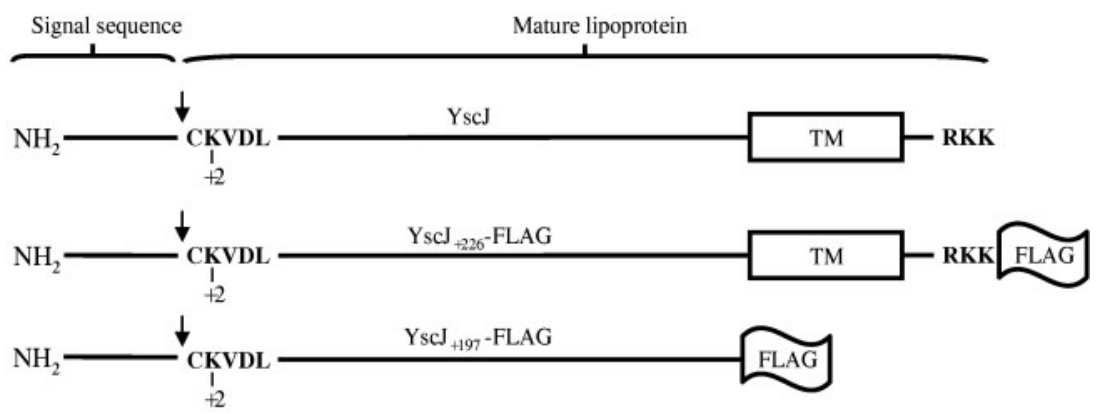

Fig. 2. Analysis of $\mathrm{YopE}$ and $\mathrm{YscJ}$ expression and YopE secretion. (a) Immunoblot analysis of whole bacterial cell (WC) and culture supernatant (S) fractions from the parent strain, the $y s c J$ deletion mutant and the yscJ deletion mutant complemented with plasmids pYscJ, $\mathrm{pYscJ}_{+226}$-FLAG and $\mathrm{pYscJ}+197-\mathrm{FLAG}$ grown in the presence $(+)$ or absence $(-)$ of $2.5 \mathrm{mM}$ calcium chloride. (b) Diagrammatic model of YscJ proteins encoded by plasmids pYscJ, pYscJ $+226^{-}$FLAG and pYscJ $+197^{-}$ FLAG. 
the deletion strain complemented with plasmid pYscJ, but not in the $y s c J$ deletion strain. FLAG-tagged YscJ gene products of approximately $28 \mathrm{kDa}$ and $25 \mathrm{kDa}$ were identified in strains carrying plasmids $\mathrm{pYsc}_{+226}$-FLAG and $\mathrm{pYscJ}_{+197}$-FLAG, respectively. These results indicate that the YscJ C-terminal TM region is essential for YscJ's function in the T3S process.

\section{Construction and analysis of ysc : : phoAlacza fusions}

The topology of YscJ was initially analysed using a set of four $y$ scJ:: phoAlac $\alpha \alpha$ gene fusions. The phoAlac $Z \alpha$ cassette encodes the mature portion of $E$. coli alkaline phosphatase (no secretion signal) fused to the LacZ $\alpha$ peptide. Plasmid vectors carrying the phoAlac $Z \alpha$ cassette in-frame with regions of $y s c J$ encoding residues +1 to $+131,+1$ to $+198,+1$ to +221 and +1 to +226 of the mature YscJ protein were constructed as described in Methods. The phoAlacZ $\alpha$ fusion joints were selected to generate YscJPhoA fusions in the middle of YscJ (pPHO-YscJ $\left.{ }_{+131}\right)$, just prior to the predicted TM domain $\left(\mathrm{pPHO}-\mathrm{YscJ}_{+198}\right)$, near the end of the TM domain ( $\mathrm{pPHO}-\mathrm{YscJ}_{+221}$ ) and at the Cterminus of YscJ following the TM domain and predicted stop-transfer sequence $\left(\mathrm{pPHO}-\mathrm{YscJ}_{+} 226\right)$. The phoAlacZ $\alpha$ fusion plasmids and control plasmid (pYscJ) were electroporated into the $Y$. pestis yscJ deletion mutant for the determination of alkaline phosphatase activity. Fusion of PhoA to regions of YscJ that are localized to the periplasmic space would be expected to allow export of the PhoA portion of the hybrid protein to the periplasm, resulting in high phosphatase activity. In contrast, fusions of PhoA to regions of YscJ localized on the cytoplasmic side of the membrane would be expected to have low phosphatase activity (Manoil et al., 1988). No determination of $\beta$-galactosidase activity was possible in $Y$. pestis (no expression of the $\omega$ fragment of $\beta$-galactosidase). Furthermore, the $y s c J:$ phoAlac $Z \alpha$ gene fusions produced significant $\beta$-galactosidase activity in $E$. coli $\mathrm{DH} 5 \alpha$, probably due to a cytoplasmic pool of unprocessed preprotein (data not shown).

The $Y$. pestis yscJ deletion strain had essentially no detectable background level of alkaline phosphatase activity (Table 1). Expression of YscJ-PhoA fusions with fusion joints located before the predicted TM domain (pPHO$\mathrm{YscJ}_{+131}$ and $\left.\mathrm{pPHO}-\mathrm{Ysc}_{+198}\right)_{\text {) exhibited high levels }}$ $(>200 \mathrm{U})$ of enzymic activity, indicating a periplasmic localization. The PhoA fusion at residue +221 , near the end of the predicted TM domain, produced an intermediate level (79.2 U) of alkaline phosphatase activity, whereas PhoA fused at the C-terminus of YscJ produced only low levels of enzymic activity (11.3 U), suggesting that the extreme C-terminus of YscJ is located in the cytoplasmic compartment. The expression of each of the YscJ-PhoA hybrid proteins in $Y$. pestis was determined by immunoblot analysis (Fig. 3). Each of the hybrid proteins was expressed; however, some proteolytic degradation of
Table 1. AP activity of $y s c J:: p h o A l a c Z \alpha$ fusions in $Y$. pestis $\Delta y s c J$

\begin{tabular}{|lc|}
\hline Plasmid & AP activity \\
\hline None & 0.0 \\
pYscJ & $0.7 \pm 0.7$ \\
pPHO-YscJ +131 & $210.6 \pm 1.9$ \\
pPHO-YscJ +198 & $201.1 \pm 1.9$ \\
pPHO-YscJ +221 & $79.2 \pm 2.3$ \\
pPHO-YscJ +226 & $11.3 \pm 1.1$ \\
\hline
\end{tabular}

${ }^{*}$ Values represent means $\pm \mathrm{SD}$ assayed in duplicate. AP, alkaline phosphatase.

all four hybrid proteins was evident. In particular, extensive degradation of the $\mathrm{YscJ}_{+226}-\mathrm{PhoA}$ hybrid protein was observed, providing additional evidence for the cytoplasmic localization of the PhoA domain of this hybrid protein.

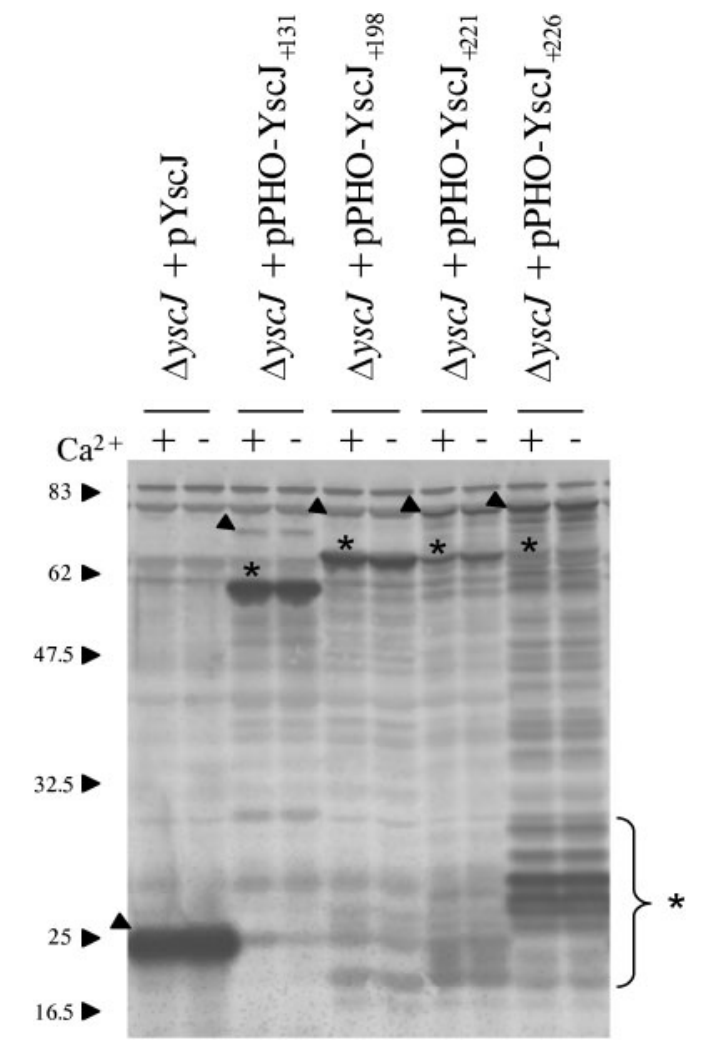

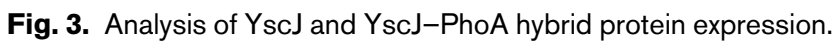
Immunoblot analysis of whole bacterial cell fractions from the $y \mathrm{sc} J$ deletion mutant complemented with plasmids $\mathrm{pYscJ}, \mathrm{pPHO}-$ $\mathrm{YscJ}_{+131}, \quad \mathrm{pPHO}-\mathrm{YscJ}_{+198}, \quad \mathrm{pPHO}-\mathrm{YscJ}_{+221}$ and $\mathrm{pPHO}-$ $\mathrm{YscJ}_{+226}$ grown in the presence $(+)$ or absence $(-)$ of $2.5 \mathrm{mM}$ calcium chloride. The location of the full-length YscJ and YscJ-Pho hybrid proteins is shown (arrowheads) as well as the location of several prominent proteolytic degradation products $\left({ }^{*}\right)$. Blots were probed with antiserum specific for YscJ. The locations of molecular mass standards $(\mathrm{kDa})$ are shown. 
PhoA is unable to fold properly in the reducing environment of the cytoplasmic compartment and is rapidly degraded by cytoplasmic proteases (Huang et al., 2001). Overall, these results support a model that predicts YscJ to be a primarily periplasmic protein that is linked to the IM by an N-terminal lipoprotein domain and by a Cterminal TM domain.

\section{The YscJ lipoprotein signal sequence}

YscJ has previously been demonstrated to be a lipoprotein (Michiels et al., 1991); however, the role of N-terminal acylation in YscJ function and membrane localization has not been investigated. The YscJ signal sequence (Fig. 1b) contains a consensus lipo-box sequence (LTG $\downarrow$ C) immediately preceding the cleavage site $(\downarrow)$. Most lipoproteins in E. coli and in other members of the Enterobacteriaceae are transported to the periplasmic face of the OM by the LolABCDE lipoprotein sorting machinery (Tokuda \& Matsuyama, 2004). Lipoproteins retained in the IM normally contain an aspartic acid residue in the +2 position, which functions as a LolCDE avoidance signal. The modified cysteine residue in position +1 of YscJ is immediately followed by the sequence $\mathrm{K}_{+2} \mathrm{~V}_{+3}$, suggesting that YscJ should be transported to the bacterial OM; however, several studies with other YscJ family members have suggested that these proteins could be IM lipoproteins (Blocker et al., 2001; Yip et al., 2005). Analysis of other YscJ/PrgK family members revealed a wide variety of amino acid residues in the $+2,+3$ and +4 positions of these proteins (Fig. 1b), suggesting that localization of these lipoproteins may occur by a novel mechanism.

To begin to investigate the role of the YscJ lipoprotein signal sequence and sorting signals in YscJ localization and function, we generated vectors encoding several YscJ signal sequence variants (Fig. 4b) and moved these plasmids into the $y s c J$ deletion mutant. The ability of these plasmids, which encode full-length versions of YscJ, to express a stable protein and to complement the defect in secretion

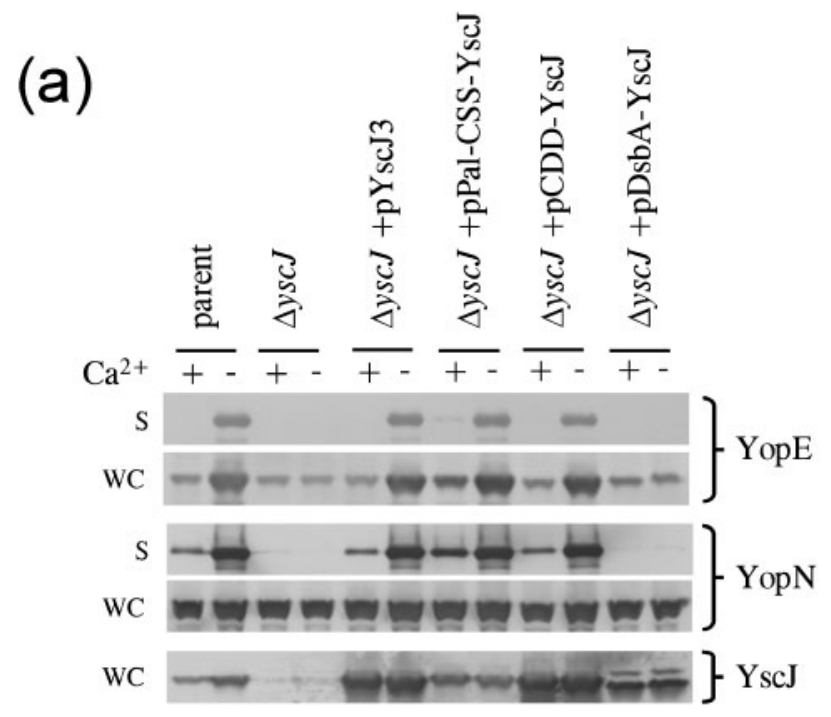

(b)

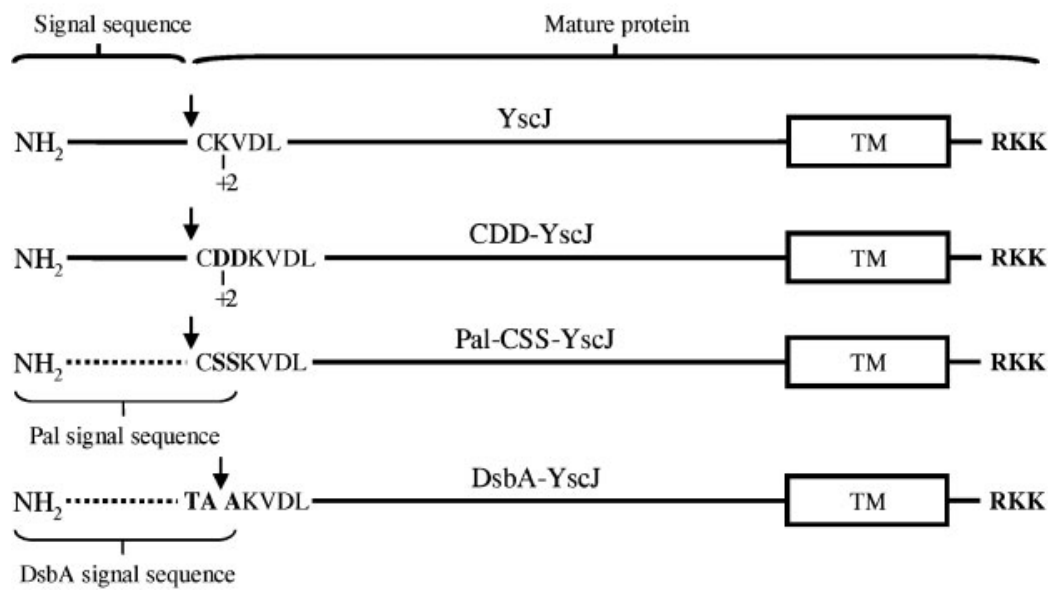

Fig. 4. Analysis of YopE, YopN and YscJ expression and YopE and YopN secretion. (a) Immunoblot analysis of whole bacterial cell (WC) and culture supernatant (S) fractions from the parent strain, the $y s c J$ deletion mutant and the yscJ deletion mutant complemented with plasmids pYscJ3, pPal-CSS-YscJ, pCDDYscJ and pDsbA-YscJ grown in the presence (+) or absence (-) of $2.5 \mathrm{mM}$ calcium chloride. (b) Diagrammatic model of YscJ proteins encoded by plasmids pYscJ3, pCDD-YscJ, pPal-CSS-YscJ and pDsbA-YscJ. 
associated with the $y s c J$ deletion mutant was evaluated (Fig. 4a).

Plasmid pYscJ3 codes for the parent YscJ protein with the wild-type (predicted $\mathrm{OM})$ sorting signal $\left(\mathrm{K}_{+2} \mathrm{~V}_{+3}\right)$; in contrast, plasmid pCDD-YscJ codes for a YscJ lipoprotein with a consensus IM sorting signal $\left(D_{+2} D_{+3}\right)$. Interestingly, both the parent YscJ protein $\left(\mathrm{K}_{+2} \mathrm{~V}_{+3}\right)$ and the YscJ protein with the consensus IM sorting signal (DD-YscJ) were able to fully complement the defect in Yop secretion associated with the $y s c J$ deletion mutant (Fig. 4a). These results suggest that YscJ contains an unusual lipoprotein signal sequence and sorting signal $\left(\mathrm{K}_{+2} \mathrm{~V}_{+3}\right)$ or that targeting of the YscJ lipoprotein to the IM or OM occurs independent of its $+2+3$ sorting signal.

To further investigate the subcellular localization and sorting of YscJ, we replaced the YscJ signal sequence with the signal sequence and $\mathrm{S}_{+2} \mathrm{~S}_{+3}$ sorting signal from the well-characterized OM-localized Pal lipoprotein (Fig. 4b). Expression of the Pal-YscJ hybrid protein (Pal-CSS-YscJ) in the $y s c J$ deletion mutant restored Yop secretion (Fig. 4a), indicating that the YscJ signal sequence could be replaced with a heterologous lipoprotein signal sequence and consensus $\left(\mathrm{S}_{+2} \mathrm{~S}_{+3}\right)$ OM sorting signal.

To confirm that YscJ, which has been demonstrated to be a lipoprotein (Michiels et al., 1991), actually requires a lipoprotein secretion signal for function, we replaced the YscJ lipoprotein signal sequence with the signal sequence from DsbA, a soluble, non-acylated periplasmic protein (Fig. $4 \mathrm{~b})$. Plasmid pDsbA-YscJ, encoding the DsbA-YscJ hybrid protein, was moved into the $y s c J$ deletion mutant. The hybrid protein was expressed and processed (presumably by the type I signal peptidase) but was not functional, indicating that YscJ localization and/or function is dependent on attachment of the N-terminus to the bacterial IM or OM.

\section{Membrane fractionation and localization of YscJ}

The subcellular localization of YscJ and truncated derivatives of YscJ was investigated by membrane fractionation using sucrose density-gradient centrifugation as described in Methods. The full-length YscJ protein expressed in the presence (Y. pestis KIM8-3002) or absence (pYscJ in Y. pestis KIM10; data not shown) of a functional T3SS was found almost exclusively in the low-density (IM) fractions of the gradient, indicating an IM location for YscJ. Control IM (YscV) and OM (YscW, YscC and OMPs) proteins from the same fractions were also analysed (Fig. 5a). The IM localization of YscJ is in agreement with recent studies by Yip et al. (2005) with EscJ, indicating that YscJ/PrgK family members are IM lipoproteins; however, IM localization of full-length YscJ could be due to the $\mathrm{N}$-terminal lipoprotein domain or to the predicted C-terminal TM domain.

To determine the subcellular localization of the YscJ Nterminal lipoprotein domain in the absence of the C-terminal TM domain, we generated a plasmid $\left.(\mathrm{pYsc}) 3_{+61}\right)$ encoding a truncated version of YscJ that is missing amino acids +62 to +226 , which include the Cterminal TM region (Fig. 5b). YscJ $_{+61}$ expressed in $Y$. pestis KIM10 fractionated with the IM-containing fractions, confirming that the wild-type YscJ signal sequence and sorting signal target $\mathrm{Ysc}_{+61}$ to the IM independent of the C-terminal TM region.

The subcellular localization of similarly truncated versions of YscJ carrying the consensus IM sorting signal (CDD$\mathrm{YscJ}_{+61}$ ) or Pal signal sequence and OM sorting signal (Pal-

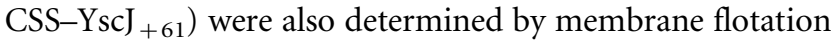
sucrose gradient centrifugation (Fig. 5a). As expected, the $\mathrm{CDD}_{-\mathrm{Ysc}}{ }_{+61}$ protein expressed in $Y$. pestis KIM10 consistently fractionated with the IM-containing fractions. Interestingly, the Pal-CSS-YscJ ${ }_{+61}$ protein, which was expressed at very high levels, was found primarily in the low-density IM-containing fractions, but also in a number of the high-density OM-containing fractions. These results suggest that the Pal signal sequence and $\mathrm{S}_{+2} \mathrm{~S}_{+3} \mathrm{OM}$ sorting signal may have had some influence on the sorting of the mature YscJ $_{+61}$ protein; however, a significant portion of this protein remained associated with the IM-containing fractions. The molecular mechanism responsible for localization of full-length YscJ and Pal-CSS-YscJ, as well as YscJ $_{+61}$ and Pal-CSS-YscJ +61 to the IM is unknown.

\section{The N-terminal 61 amino acids of $\mathrm{YscJ}$ are required for IM localization of YscJ}

Alteration of the amino-acid residues immediately following the +1 acylated cysteine did not modify the subcellular localization of Yscj; therefore, we hypothesized that localization of the YscJ lipoprotein moiety to the IM was directed by the formation of a stable domain as has been proposed for other lipoproteins (Robichon et al., 2003). Interestingly, EscJ, another YscJ family member, has been shown to consist of two distinct domains, corresponding to YscJ residues +1 to +59 and +85 to +195 , that are connected by a linker region located between amino acids +60 and +85 (Crepin et al., 2005). To evaluate the role of the YscJ N-terminal domain in lipoprotein localization and to localize the minimal region of YscJ required for this localization, we generated plasmids encoding the $\mathrm{N}$ terminal $+25,+42$ and +61 amino acids of YscJ fused to a C-terminal FLAG epitope tag (Fig. 6b). The pYscJ $+61^{-}$ FLAG, $\mathrm{pYsc}_{+42}$-FLAG and $\mathrm{pYscJ}_{+25}$-FLAG vectors were moved into $Y$. pestis KIM10 and the subcellular location of the FLAG-tagged YscJ proteins was determined by flotation sucrose density-gradient centrifugation. As expected, the $\mathrm{YscJ}_{+61}$-FLAG protein was primarily found in the IMcontaining fractions (Fig. 6a). In contrast, the $\mathrm{YscJ}_{+42^{-}}$ FLAG and $\mathrm{Ysc}_{+25}$-FLAG proteins associated primarily with the OM-containing fractions, indicating that the $\mathrm{N}$ terminal 61 residues of YscJ, which are predicted to fold into a stable domain, are required for IM localization.

Truncations that prevent the formation of a properly folded protein domain often result in an increased susceptibility to proteolytic degradation. The proteolytic 
(a)

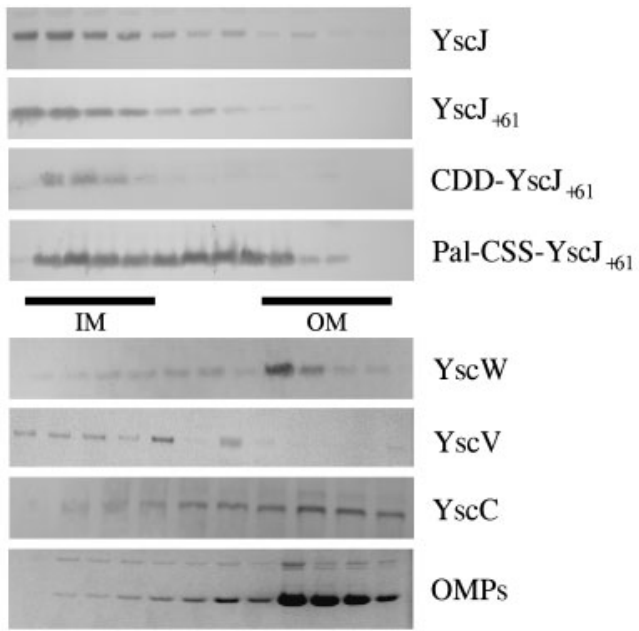

(b)

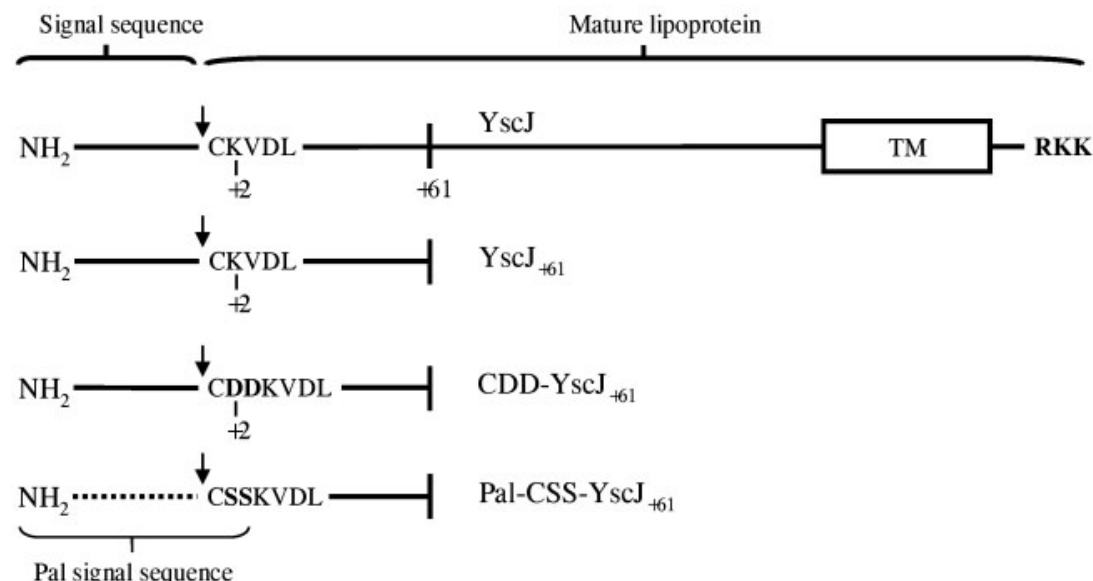

Fig. 5. Localization of membrane proteins expressed in $Y$. pestis. (a) Membranes isolated from $Y$. pestis KIM8-3002 or KIM10 carrying plasmids pYscJ3, pYscJ3 $3_{+61}, p C D D-Y s c J_{+61}$ or pPAL-CSS-YscJ +61 were separated by flotation sucrose density-gradient centrifugation. Proteins in the collected fractions were analysed by SDS-PAGE and immunoblot analysis with anti-YscJ antibodies. Control IM (YscV) and $\mathrm{OM}$ (YscC and $\mathrm{YscW}$ ) proteins from $Y$. pestis KIM8-3002 were detected by immunoblot analysis with anti-YscV, anti-YscC and anti-YscW antibodies. Major OM proteins (OMPs) from $Y$. pestis KIM10 were detected by Coomassie blue staining. (b) Diagrammatic model of YscJ proteins encoded by plasmids pYscJ3, $\quad$ Y YscJ3 ${ }_{+61}, \quad p C D D-Y s c J_{+61}$ and pPAL-CSS-YscJ +61 . stability of the $\mathrm{YscJ}_{+61^{-}}$-FLAG, $\mathrm{YscJ}_{+42^{-}}$FLAG and $\mathrm{YscJ}_{+25^{-}}$ FLAG proteins was determined by quantifying the amount of each protein after blocking new synthesis via the addition of chloramphenicol. Samples taken immediately (time 0 ) and at $15 \mathrm{~min}, 30 \mathrm{~min}, 1 \mathrm{~h}$ and $2 \mathrm{~h}$ after the addition of chloramphenicol were analysed by immunoblotting with anti-FLAG antibody. The $\mathrm{YscJ}_{+61}$-FLAG protein, which contains the complete YscJ N-terminal domain, was relatively stable; in contrast, the $\mathrm{YscJ}_{+42^{-}}$ FLAG and $\mathrm{Ysc}_{+25}$-FLAG proteins were rapidly degraded, indicating that these proteins were probably not properly folded (data not shown). These results suggest that a complete and properly folded N-terminal domain is required for the retention of YscJ in the IM.

\section{Evaluation of lipoprotein sorting using YscJ-YscW hybrid proteins}

$\mathrm{YscW}$ is an $\mathrm{OM}$ lipoprotein chaperone that is required for $\mathrm{OM}$ localization and proper multimerization of the $\mathrm{YscC}$ secretin, an essential component of the T3SS (Burghout et al., 2004). To further investigate the role of the YscJ
$\mathrm{N}$-terminal domain in lipoprotein localization, we evaluated the ability of various YscJ $\mathrm{N}$-terminal regions to target the mature domain of YscW to the OM. Constructs encoding the mature domain of YscW (amino acids +2 to +116 ) fused to the YscJ signal sequence and residues +1 to $+5\left(\mathrm{YscJ}_{+5}-\mathrm{YscW}\right),+1$ to $+25\left(\mathrm{Ysc}_{+25}-\mathrm{YscW}\right),+1$ to $+42\left(\mathrm{YscJ}_{+42}-\mathrm{YscW}\right)$ or +1 to $+61\left(\mathrm{YscJ}_{+61}-\mathrm{YscW}\right)$ of the mature YscJ protein were generated (Fig. 7c) and moved into a $y s c W$ deletion mutant. As expected, plasmid pYscW, which carries the wild-type $y s c W$ gene $\left(\mathrm{A}_{+2} \mathrm{~T}_{+3}\right)$, completely restored calcium-regulated Yop secretion (Fig. 7a). Likewise, plasmids expressing YscJ-YscW hybrid proteins containing the YscJ signal sequence and the $\mathrm{N}$ terminal +1 to $+5,+1$ to +25 or +1 to +42 residues of YscJ fused to the mature domain of YscW were able to restore Yop secretion, confirming that the wild-type YscJ signal sequence and $\mathrm{K}_{+2} \mathrm{~V}_{+3}$ sorting signal can direct the sorting of a lipoprotein to the OM in the absence of the intact YscJ $\mathrm{N}$-terminal domain. In contrast, plasmid $\mathrm{pYscJ}_{+61}-\mathrm{YscW}$ expressed a stable $\mathrm{Ysc}_{+61}-\mathrm{YscW}_{\mathrm{s}}$ hybrid protein that was unable to complement the defect in Yop secretion, most likely because the $\mathrm{YscJ}_{+61}$ discrete 
(a)

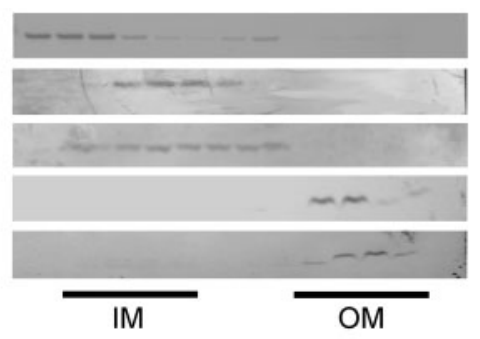

YscJ

$\mathrm{YscJ}_{+61}$

$\mathrm{YscJ}_{+61}-\mathrm{FLAG}$

$\mathrm{YscJ}_{+42}$-FLAG

$\mathrm{YscJ}_{+25}$-FLAG

OMPs (b)

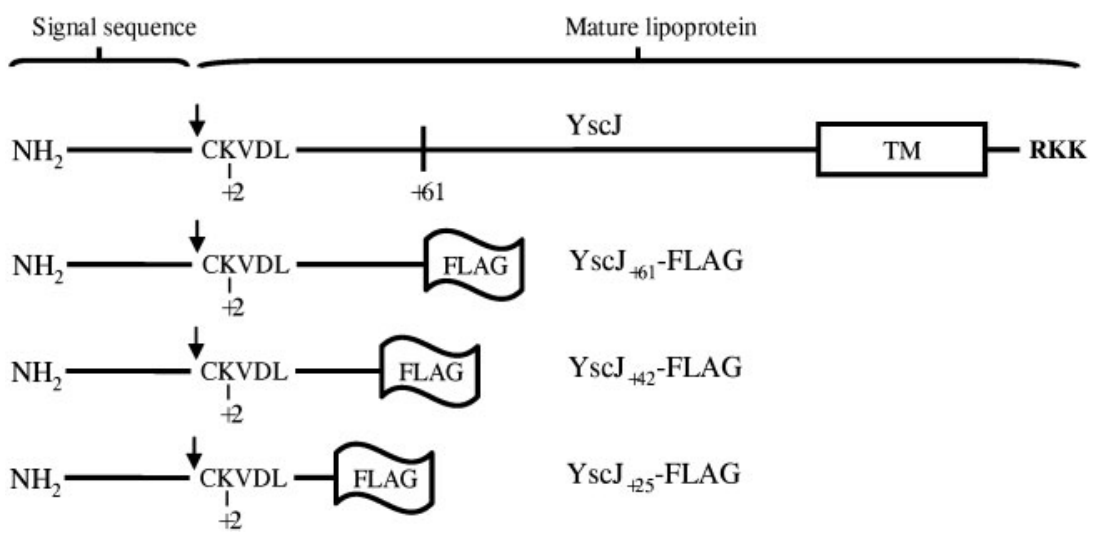

Fig. 6. Localization of membrane proteins expressed in $Y$. pestis. (a) Membranes isolated from $Y$. pestis KIM10 carrying plasmids pYscJ3, $\quad$ PYscJ3 ${ }_{+61}, \quad$ pYscJ +61 -FLAG, pYscJ $_{+42}$-FLAG or pYscJ +25 -FLAG were separated by flotation sucrose density-gradient centrifugation. Proteins in the collected fractions were analysed by SDS-PAGE and immunoblot analysis with anti-YscJ or antiFLAG antibodies. Major OM proteins (OMPs) from $Y$. pestis $\mathrm{KIM} 10$ were detected by Coomassie blue staining. (b) Diagrammatic model of YscJ proteins encoded by plasmids pYscJ3, pYscJ +61 -FLAG, pYscJ $+42-$ FLAG or pYscJ +25 -FLAG.
$\mathrm{N}$-terminal domain prevented sorting of the YscW domain to the OM. Flotation density-gradient centrifugation was used to determine the subcellular localization of the $\mathrm{YscJ}_{+5}-\mathrm{YscW}$ and the $\mathrm{YscJ}_{+61}-\mathrm{YscW}$ proteins (Fig. 7b). The functional YscJ $+5^{-}$YscW protein primarily localized to the OM-containing fractions, whereas the non-functional $\mathrm{YscJ}_{+61}-\mathrm{YscW}$ protein localized primarily with the IMcontaining fractions. These results support a role for the $\mathrm{N}$ terminal YscJ domain in retaining YscJ (and the YscJ $+61^{-}$ YscW hybrid protein) in the IM.

\section{Preliminary analysis of the state of YscJ acylation}

As discussed above, the transport of lipoproteins to the OM by the Lol system in E. coli can be avoided by the presence of an aspartic acid residue in the +2 position. Recognition and transport of lipoproteins also require that the lipoprotein is fully acylated (Fukuda et al., 2002; Robichon et al., 2005). Previous studies using $\left[{ }^{3} \mathrm{H}\right]$ palmitic acid to specifically label lipoproteins have demonstrated that YscJ is acylated (Michiels et al., 1991); however, the extent of YscJ acylation has not been determined. The final step in lipoprotein acylation is catalysed by apolipoprotein $N$-acyltransferase, which adds a third acyl chain directly to the amino group of the modified N-terminal cysteine residue. The presence or absence of this modification can be determined by subjecting the lipoprotein to $\mathrm{N}$-terminal sequence determination, which is dependent upon the presence of a free $\mathrm{N}$-terminal amino group.
A functional YscJ-6x-His protein was expressed in the $y s c J$ deletion mutant and purified by nickel-affinity chromatography. The purified YscJ-6x-His protein was subjected to N-terminal sequence determination. The sequence obtained, (-) K V D L, confirmed that the YscJ-6x-His protein was processed and cleaved at the expected location. The ability to obtain an N-terminal sequence by Edman degradation depends upon the presence of a free $\mathrm{N}$ terminal amino group. Thus, as pointed out previously for MxiJ by Blocker et al. (2001), these results indicate that a significant portion of the purified YscJ-6x-His protein was not $N$-acylated. The lack of $N$-acylation provides a possible explanation for the retention of YscJ in the IM. Thus, the processing of YscJ and other YscJ/PrgK family lipoproteins may represent a divergence from the normally efficient lipoprotein processing/sorting pathway previously characterized for E. coli lipoproteins.

\section{Role of YscJ lipid moiety and C-terminal TM region in YscJ function}

Previous studies (Yip et al., 2005) and results presented above indicate that YscJ family members are IM lipoproteins that require at least partial acylation for function; however, the function of the N-terminal acylation has not been determined. In most instances, the lipid moiety of a lipoprotein serves simply as an anchor that attaches a proteinaceous domain to a specific cellular membrane; however, proteins intimately associated with membranes can be attached by a 


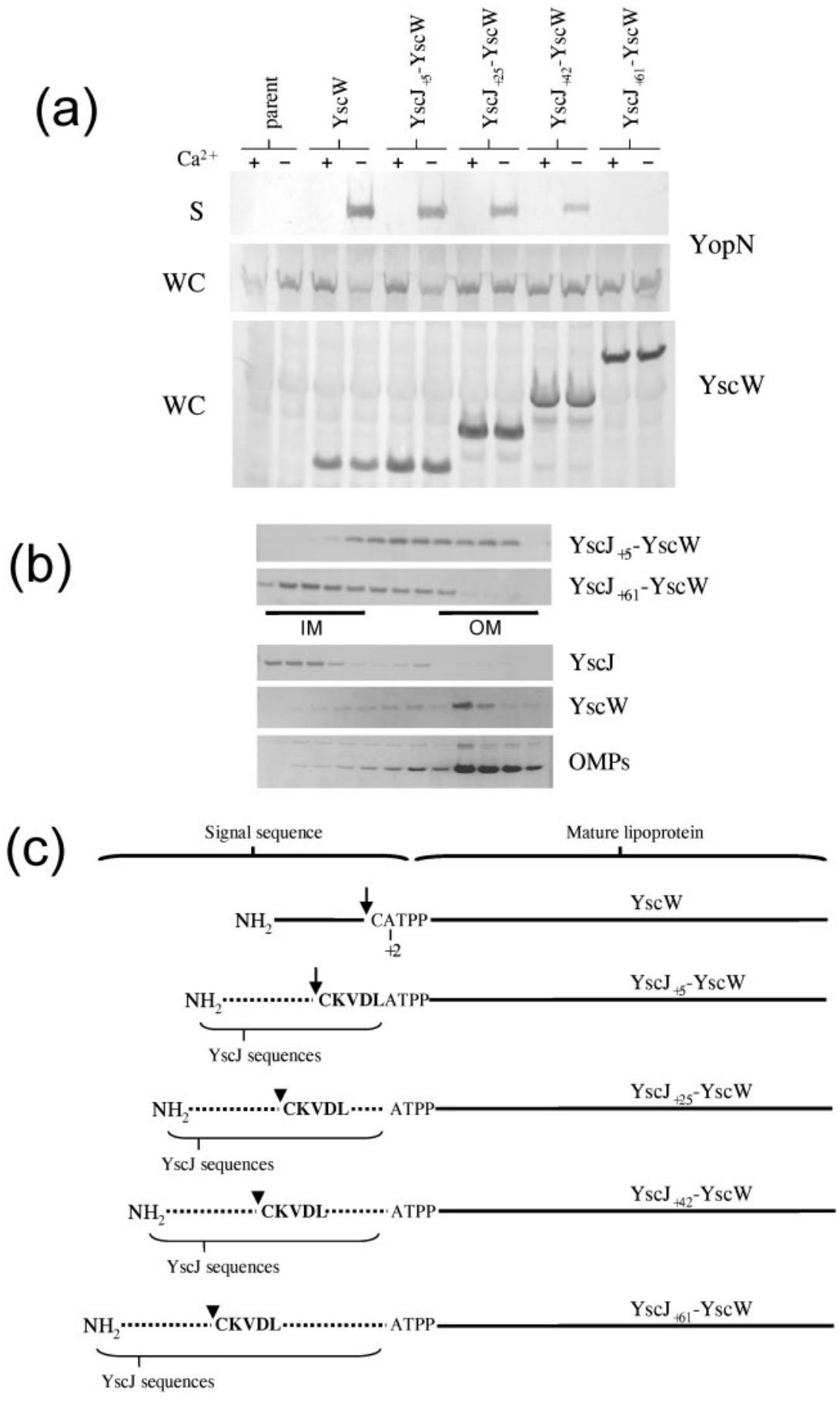

Fig. 7. Localization and function of YscJ secretion/sorting signal-YscW hybrid proteins in $Y$. pestis. (a) Immunoblot analysis of whole bacterial cell (WC) and culture supernatant (S) fractions from the parent strain, a $y s c W$ deletion mutant, and the $y s c W$ deletion mutant complemented with plasmids $\mathrm{pYscW}$, $\mathrm{pYscJ}_{+5}-\mathrm{YscW}_{\mathrm{sc}} \mathrm{pYscJ}+25^{-} \mathrm{YscW}_{\mathrm{sc}} \mathrm{pYscJ}+42^{-}$ YscW and $\mathrm{pYscJ}+61^{-Y s c W}$ grown with $(+)$ or without (-) $2.5 \mathrm{mM}$ calcium chloride. (b) Membranes isolated from the parent strain or the $y s c W$ deletion mutant carrying plasmids $\mathrm{pYscJ}_{+5}-\mathrm{YscW}$ or $\mathrm{pYscJ}_{+61}-\mathrm{YscW}$ were separated by flotation sucrose density-gradient centrifugation. Proteins were analysed by SDS-PAGE and immunoblot analysis with anti-YscJ or anti-YscW antibodies. Control IM (YscJ) and OM (YscW) proteins from the parent strain were detected by immunoblot analysis with anti-YscJ or anti-YscW antibodies. Major OM proteins (OMPs) from the $y s c W$ deletion mutant were detected by Coomassie blue staining. (c) Diagrammatic model of YscW and YscJ-YscW hybrid proteins encoded by plasmids pYscW, pYscJ $+5^{-}$ YscW, $\quad$ YYscJ $+25-Y s c W, \quad p Y s c J_{+42}-Y s c W$ and $\mathrm{pYscJ}+61-\mathrm{YscW}$.

variety of mechanisms including protein-protein interactions, lipid moieties or TM domains. If the YscJ lipid moiety serves simply as an IM anchor sequence it might also be possible to anchor the $\mathrm{N}$-terminus of YscJ through a different mechanism. Indeed, the flagellar MS-ring protein, FliF, which shares significant amino acid sequence identity with YscJ, is not a lipoprotein, but instead has N-terminal and Cterminal TM domains (Ueno et al., 1994).

To begin to examine the role of the YscJ lipid moiety, we replaced the YscJ signal sequence and +1 cysteine with the first TM region (in-to-out) from the integral IM protein YscV (Plano et al., 1991) (Fig. 8b). Similarly, to determine if the YscJ C-terminal TM domain plays a specific role in YscJ function, we replaced the C-terminal TM domain of YscJ with the second TM region (out-to-in) of YscV. Plasmids encoding the $\mathrm{YscV}_{\mathrm{TM} 1}-\mathrm{YscJ}$ and $\mathrm{YscJ}-\mathrm{YscV}_{\mathrm{TM}}$ proteins were moved into the $y s c J$ deletion strain. Both plasmids encoded stable proteins that completely complemented the defect in Yop secretion (Fig. 8a). These studies suggest that the YscJ N-terminal lipid moiety and the Cterminal TM region function to attach or anchor the YscJ 
(a)

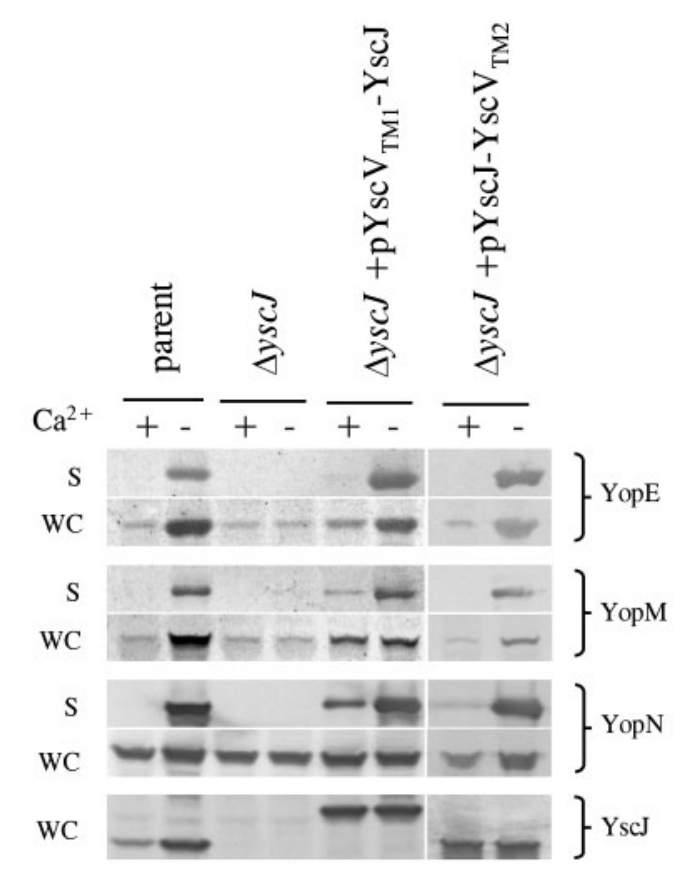

(b)
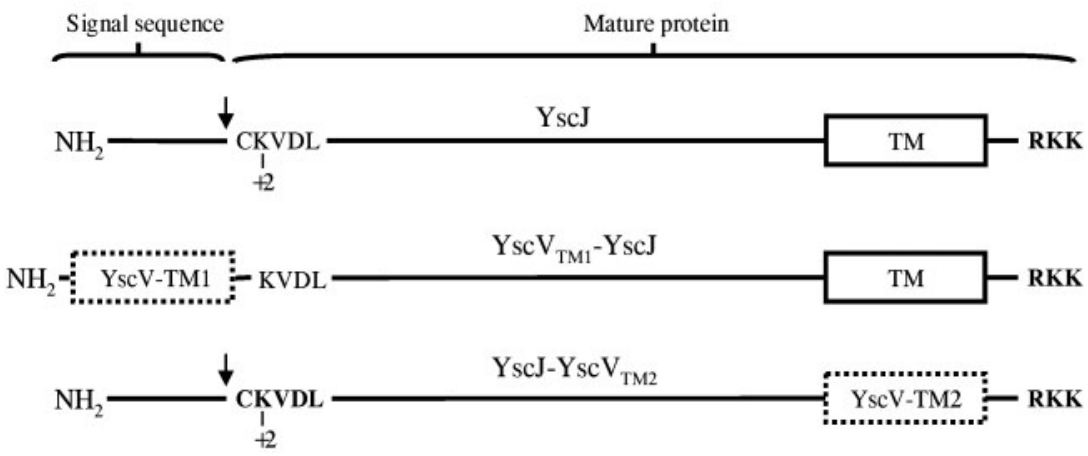

Fig. 8. Analysis of YopE, YopM, YopN and YscJ expression and YopE, YopM and YopN secretion. (a) Immunoblot analysis of whole bacterial cell (WC) and culture supernatant (S) fractions from the parent strain, the $y s c J$ deletion mutant and the yscJ deletion mutant complemented with plasmids $\mathrm{pYscV}_{\mathrm{TM} 1}-\mathrm{YscJ}_{\mathrm{sc}}$ and pYscJ-YscV $\mathrm{TM}_{\mathrm{TM}}$ grown in the presence $(+)$ or absence (-) of $2.5 \mathrm{mM}$ calcium chloride. (b) Diagrammatic model of YscJ proteins encoded by plasmids PCD1, $\mathrm{pYscV}_{\mathrm{TM} 1}-\mathrm{YscJ}_{\mathrm{sc}}$ and $\mathrm{pYscJ}-\mathrm{YscV}_{\mathrm{TM} 2}$.

periplasmic domains to the IM and have no separate essential function in the T3S process.

\section{DISCUSSION}

Previous studies have shown that YscJ is a lipoprotein that is required for the assembly of a functional T3S apparatus (Allaoui et al., 1995; Michiels et al., 1991). Recent evidence also suggests that members of the YscJ/PrgK family multimerize to form a ring-like structure analogous to the flagellar MS-ring (Yip et al., 2005). The YscJ ring-like structure is probably located in the periplasmic space anchored to the bacterial IM by Ysc)'s N-terminal lipid moiety and C-terminal TM domain. Evidence presented here provides support for several aspects of this model. Results obtained using YscJ-PhoA-LacZ $\alpha$ hybrid proteins indicate that the majority of YscJ is located in the periplasmic space. In contrast, a PhoA-LacZ $\alpha$ fusion following the Arg-Lys-Lys sequence located at the
C-terminus of YscJ had extremely low alkaline phosphatase activity, indicating a cytoplasmic location. These results indicate that the YscJ C-terminal hydrophobic region is a TM domain that probably assists in anchoring the primarily periplasmic YscJ ring to the bacterial IM.

Interestingly, EscJ from enteropathogenic E. coli lacks a Cterminal hydrophobic domain (Crepin et al., 2005), suggesting that this region, which is found in most YscJ/ PrgK family members, may not be required for function. To evaluate the role of the C-terminal TM domain in YscJ expression, stability and function we created a YscJ deletion mutant that lacked this specific structural feature. A YscJ mutant lacking the C-terminal TM domain and Arg-LysLys anchor sequence was non-functional. Interestingly, the C-terminal TM region of YscJ could be functionally replaced using a heterologous TM domain from another integral IM protein, indicating that the YscJ TM domain functions primarily as an anchor and does not appear to have any additional sequence-specific functions. 
Multiple lines of evidence indicate that YscJ/PrgK family members are lipoproteins. These proteins all carry consensus lipoprotein signal peptidase recognition/cleavage sites, and labelling with $\left[{ }^{14} \mathrm{C}\right]-$ or $\left[{ }^{3} \mathrm{H}\right]$ palmitate has been directly demonstrated for several of these proteins, including YscJ (Allaoui et al., 1992; Michiels et al., 1991). Nevertheless, the exact nature of N-terminal acylation has not been determined for any $\mathrm{YscJ} / \mathrm{PrgK}$ family member, and evidence suggests that these proteins as a family are not fully acylated (Blocker et al., 2001). In fact, the ability to obtain N-terminal sequence information from YscJ, as well as MxiJ and PrgK (no membrane localization data are available for these proteins), indicates that the $\mathrm{N}$-terminal amino group of these lipoproteins is normally not acylated (Blocker et al., 2001; Kubori et al., 1998). In fact, MxiJ and PrgJ obtained directly from purified assembled NCs provided $\mathrm{N}$-terminal sequence information, suggesting that the absence of $\mathrm{N}$-acylation is not an artefact related to overexpression of these lipoproteins. Importantly, the Lol transport system is specific for fully acylated lipoproteins; therefore, incompletely acylated lipoproteins cannot be transported to the OM (Fukuda et al., 2002; Robichon et al., 2005). Thus, one explanation for the IM localization of YscJ/PrgK family members is that addition of the third acyl chain by apolipoprotein $\mathrm{N}$-acyltransferase is blocked by an as-yet-unidentified mechanism. If correct, this hypothesis, originally proposed by Blocker et al. (2001), would provide an explanation for why YscJ and other YscJ/ PrgK family members are localized to the IM regardless of the amino-acid residues in positions +2 or +3 . To our knowledge, YscJ, PrgK and MxiJ represent the first documented examples of a natural mechanism to prevent complete acylation of a lipoprotein.

Membrane flotation sucrose density-gradient centrifugation experiments confirmed that YscJ was localized to the $Y$. pestis IM and that IM localization was not dependent upon the C-terminal TM domain. Providing the secretion signal and $\mathrm{OM}$ sorting signal from the OM-localized $\mathrm{Pal}$ lipoprotein did not disrupt YscJ function or localization to the IM, confirming that YscJ localization occurs independent of the $+2+3$ lipoprotein sorting signals. Interestingly, the localization of YscJ to the IM was dependent upon an intact YscJ N-terminal domain (residues +1 to +61 ). The wild-type $\mathrm{YscJ} \mathrm{K}_{+2} \mathrm{~V}_{+3} \mathrm{OM}$ sorting signal was recognized and directed the encoded lipoprotein to the OM only when provided in the context of an incomplete YscJ N-terminal domain (YscJ residues +1 to $+5,+1$ to +25 or +1 to +42 ). These results suggest that one function of the YscJ $\mathrm{N}$-terminal domain may be to block or prevent complete acylation of YscJ and thus ensure that YscJ remains in the IM. As mentioned, no natural mechanism has been identified that specifically prevents $\mathrm{N}$-terminal acylation of a specific lipoprotein. Thus, the mechanism by which the $\mathrm{N}$-terminal domain of YscJ prevents $\mathrm{N}$-terminal acylation is unknown. It is possible that the YscJ Nterminal domain could block access of apolipoprotein $\mathrm{N}$ acyltransferase or direct rapid assembly of YscJ into a multimer that is no longer a substrate for this enzyme.
At this time, we have no explanation as to why YscJ/PrgK family members have a unique mechanism for localization to the IM. Indeed, a few YscJ/PrgK family proteins, such as SsaJ and HrcJ (Fig. 1b), have an Asp in position +2 and would be expected to be sorted to the IM; however, it is unknown if these lipoproteins are fully acylated. One possible explanation for this unique localization mechanism is that YscJ function or assembly may be incompatible with complete acylation. However, this explanation seems unlikely considering that the $\mathrm{N}$-terminal signal sequence and consensus lipoprotein signal peptidase recognition/cleavage site of YscJ can be functionally substituted for by a TM domain from an integral IM protein. It is also unlikely that the interaction of YscJ with other T3S apparatus components plays a role in retaining YscJ in the IM, as localization of YscJ is similar in the presence or absence of plasmid $\mathrm{pCD} 1$, which encodes the T3SS. Understanding the mechanism of YscJ localization will require a detailed analysis of its acylation state and its interaction with the key enzymes involved in lipoprotein acylation and sorting.

\section{ACKNOWLEDGEMENTS}

This work was supported by Public Health Service grant AI-39575 from the National Institutes of Health.

\section{REFERENCES}

Alexeyev, M. F. \& Winkler, H. H. (1999). Membrane topology of the Rickettsia prowazekii ATP/ADP translocase revealed by novel dual pho-lac reporters. J Mol Biol 285, 1503-1513.

Ali, S. A. \& Steinkasserer, A. (1995). PCR-ligation-PCR mutagenesis: a protocol for creating gene fusions and mutations. Biotechniques 18, 746-750.

Allaoui, A., Sansonetti, P. J. \& Parsot, C. (1992). MxiJ, a lipoprotein involved in secretion of Shigella Ipa invasins, is homologous to YscJ, a secretion factor of the Yersinia Yop proteins. J Bacteriol 174, 7661-7669.

Allaoui, A., Schulte, R. \& Cornelis, G. R. (1995). Mutational analysis of the Yersinia enterocolitica virC operon: characterization of $y s c E, F$, $G, I, J, K$ required for Yop secretion and $y s c H$ encoding YopR. Mol Microbiol 18, 343-355.

Blocker, A., Gounon, P., Larquet, E., Niebuhr, K., Cabiaux, V., Parsot, C. \& Sansonetti, P. (1999). The tripartite type III secreton of Shigella flexneri inserts IpaB and IpaC into host membranes. J Cell Biol 147, 683-693.

Blocker, A., Jouihri, N., Larquet, E., Gounon, P., Ebel, F., Parsot, C., Sansonetti, P. \& Allaoui, A. (2001). Structure and composition of the Shigella flexneri "needle complex", a part of its type III secreton. Mol Microbiol 39, 652-663.

Burghout, P., Beckers, F., de Wit, E., van Boxtel, R., Cornelis, G. R., Tommassen, J. \& Koster, M. (2004). Role of the pilot protein YscW in the biogenesis of the YscC secretin in Yersinia enterocolitica. J Bacteriol 186, 5366-5375.

Cambau, E., Bordon, F., Collatz, E. \& Gutmann, L. (1993). Novel gyrA point mutation in a strain of Escherichia coli resistant to fluoroquinolones but not to nalidixic acid. Antimicrob Agents Chemother 37, 1247-1252. 
Cornelis, G. R. (2002). The Yersinia Ysc-Yop virulence apparatus. Int J Med Microbiol 291, 455-462.

Crago, A. M. \& Koronakis, V. (1998). Salmonella InvG forms a ringlike multimer that requires the InvH lipoprotein for outer membrane localization. Mol Microbiol 30, 47-56.

Crepin, V. F., Prasannan, S., Shaw, R. K., Wilson, R. K., Creasey, E., Abe, C. M., Knutton, S., Frankel, G. \& Matthews, S. (2005). Structural and functional studies of the enteropathogenic Escherichia coli type III needle complex protein EscJ. Mol Microbiol 55, 1658-1670.

Fukuda, A., Matsuyama, S., Hara, T., Nakayama, J., Nagasawa, H. \& Tokuda, H. (2002). Aminoacylation of the $\mathrm{N}$-terminal cysteine is essential for Lol-dependent release of lipoproteins from membranes but does not depend on lipoprotein sorting signals. J Biol Chem 277, 43512-43518.

Goguen, J. D., Yother, J. \& Straley, S. C. (1984). Genetic analysis of the low calcium response in Yersinia pestis $\mathrm{Mu} \mathrm{d} 1$ (Ap lac) insertion mutants. J Bacteriol 160, 842-848.

Guzman, L. M., Belin, D., Carson, M. J. \& Beckwith, J. (1995). Tight regulation, modulation, and high-level expression by vectors containing the arabinose PBAD promoter. J Bacteriol 177, 4121-4130.

Haddix, P. L. \& Straley, S. C. (1992). Structure and regulation of the Yersinia pestis yscBCDEF operon. J Bacteriol 174, 4820-4828.

Hara, T., Matsuyama, S. \& Tokuda, H. (2003). Mechanism underlying the inner membrane retention of Escherichia coli lipoproteins caused by Lol avoidance signals. J Biol Chem 278, 40408-40414.

Hayashi, S. \& Wu, H. C. (1990). Lipoproteins in bacteria. J Bioenerg Biomembr 22, 451-471.

Huang, H. C., Sherman, M. Y., Kandror, O. \& Goldberg, A. L. (2001). The molecular chaperone DnaJ is required for the degradation of a soluble abnormal protein in Escherichia coli. J Biol Chem 276, 3920-3928.

Hueck, C. J. (1998). Type III protein secretion systems in bacterial pathogens of animals and plants. Microbiol Mol Biol Rev 62, 379-433.

Jackson, M. W. \& Plano, G. V. (1999). DsbA is required for stable expression of outer membrane protein $\mathrm{YscC}$ and for efficient Yop secretion in Yersinia pestis. J Bacteriol 181, 5126-5130.

Juris, S. J., Shao, F. \& Dixon, J. E. (2002). Yersinia effectors target mammalian signalling pathways. Cell Microbiol 4, 201-211.

Kimbrough, T. G. \& Miller, S. I. (2000). Contribution of Salmonella typhimurium type III secretion components to needle complex formation. Proc Natl Acad Sci U S A 97, 11008-11013.

Koster, M., Bitter, W., de Cock, H., Allaoui, A., Cornelis, G. R. \& Tommassen, J. (1997). The outer membrane component, YscC, of the Yop secretion machinery of Yersinia enterocolitica forms a ringshaped multimeric complex. Mol Microbiol 26, 789-797.

Kubori, T., Matsushima, Y., Nakamura, D., Uralil, J., Lara-Tejero, M., Sukhan, A., Galan, J. E. \& Aizawa, S. I. (1998). Supramolecular structure of the Salmonella typhimurium type III protein secretion system. Science 280, 602-605.

Macnab, R. M. (1999). The bacterial flagellum: reversible rotary propellor and type III export apparatus. J Bacteriol 181, 7149-7153.

Manoil, C., Boyd, D. \& Beckwith, J. (1988). Molecular genetic analysis of membrane protein topology. Trends Genet 4, 223-226.

Marlovits, T. C., Kubori, T., Sukhan, A., Thomas, D. R., Galan, J. E. \& Unger, V. M. (2004). Structural insights into the assembly of the type III secretion needle complex. Science 306, 1040-1042.

Masuda, K., Matsuyama, S. \& Tokuda, H. (2002). Elucidation of the function of lipoprotein-sorting signals that determine membrane localization. Proc Natl Acad Sci U S A 99, 7390-7395.

Matsuyama, S., Tajima, T. \& Tokuda, H. (1995). A novel periplasmic carrier protein involved in the sorting and transport of Escherichia coli lipoproteins destined for the outer membrane. EMBO J 14, 3365-3372.

Matsuyama, S., Yokota, N. \& Tokuda, H. (1997). A novel outer membrane lipoprotein, LolB (HemM), involved in the LolA (p20)dependent localization of lipoproteins to the outer membrane of Escherichia coli. EMBO J 16, 6947-6955.

Michiels, T., Vanooteghem, J. C., Lambert de Rouvroit, C., China, B., Gustin, A., Boudry, P. \& Cornelis, G. R. (1991). Analysis of $\operatorname{vir} C$, an operon involved in the secretion of Yop proteins by Yersinia enterocolitica. J Bacteriol 173, 4994-5009.

Miller, V. L. \& Mekalanos, J. J. (1988). A novel suicide vector and its use in construction of insertion mutations: osmoregulation of outer membrane proteins and virulence determinants in Vibrio cholerae requires toxR. J Bacteriol 170, 2575-2583.

Pallen, M. J., Beatson, S. A. \& Bailey, C. M. (2005). Bioinformatics, genomics and evolution of non-flagellar type-III secretion systems: a Darwinian perspective. FEMS Microbiol Rev 29, 201-229.

Plano, G. V. \& Straley, S. C. (1995). Mutations in $y s c C$, $y s c D$, and $y s c G$ prevent high-level expression and secretion of $\mathrm{V}$ antigen and Yops in Yersinia pestis. J Bacteriol 177, 3843-3854.

Plano, G. V., Barve, S. S. \& Straley, S. C. (1991). LcrD, a membranebound regulator of the Yersinia pestis low-calcium response. J Bacteriol 173, 7293-7303.

Robichon, C., Bonhivers, M. \& Pugsley, A. P. (2003). An intramolecular disulphide bond reduces the efficacy of a lipoprotein plasma membrane sorting signal. Mol Microbiol 49, 1145-1154.

Robichon, C., Vidal-Ingigliardi, D. \& Pugsley, A. P. (2005). Depletion of apolipoprotein $\mathrm{N}$-acyltransferase causes mislocalization of outer membrane lipoproteins in Escherichia coli. J Biol Chem 280, 974-983.

Rosqvist, R., Magnusson, K. E. \& Wolf-Watz, H. (1994). Target cell contact triggers expression and polarized transfer of Yersinia YopE cytotoxin into mammalian cells. EMBO J 13, 964-972.

Sekiya, K., Ohishi, M., Ogino, T., Tamano, K., Sasakawa, C. \& Abe, A. (2001). Supermolecular structure of the enteropathogenic Escherichia coli type III secretion system and its direct interaction with the EspAsheath-like structure. Proc Natl Acad Sci U S A 98, 11638-11643.

Skrzypek, E., Haddix, P. L., Plano, G. V. \& Straley, S. C. (1993). New suicide vector for gene replacement in yersiniae and other gramnegative bacteria. Plasmid 29, 160-163.

Stoker, N. G., Fairweather, N. F. \& Spratt, B. G. (1982). Versatile lowcopy-number plasmid vectors for cloning in Escherichia coli. Gene 18, 335-341.

Terada, M., Kuroda, T., Matsuyama, S. I. \& Tokuda, H. (2001). Lipoprotein sorting signals evaluated as the LolA-dependent release of lipoproteins from the cytoplasmic membrane of Escherichia coli. J Biol Chem 276, 47690-47694.

Tokuda, H. \& Matsuyama, S. (2004). Sorting of lipoproteins to the outer membrane in E. coli. Biochim Biophys Acta 1693, 5-13.

Tokunaga, M., Tokunaga, H. \& Wu, H. C. (1982). Post-translational modification and processing of Escherichia coli prolipoprotein in vitro. Proc Natl Acad Sci U S A 79, 2255-2259.

Troisfontaines, P. \& Cornelis, G. R. (2005). Type III secretion: more systems than you think. Physiology (Bethesda) 20, 326-339.

Ueno, T., Oosawa, K. \& Aizawa, S. (1994). Domain structures of the MS ring component protein (FliF) of the flagellar basal body of Salmonella typhimurium. J Mol Biol 236, 546-555.

Une, T. \& Brubaker, R. R. (1984). In vivo comparison of avirulent $\mathrm{Vwa}^{-}$and $\mathrm{Pgm}^{-}$or $\mathrm{Pst}^{\mathrm{r}}$ phenotypes of yersiniae. Infect Immun 43, 895-900. 
Viboud, G. I. \& Bliska, J. B. (2005). Yersinia outer proteins: role in modulation of host cell signalling responses and pathogenesis. Anпu Rev Microbiol 59, 69-89.

Yakushi, T., Masuda, K., Narita, S., Matsuyama, S. \& Tokuda, H. (2000). A new ABC transporter mediating the detachment of lipidmodified proteins from membranes. Nat Cell Biol 2, 212-218.

Yamaguchi, K., Yu, F. \& Inouye, M. (1988). A single amino acid determinant of the membrane localization of lipoproteins in E. coli. Cell 53, 423-432.
Yip, C. K. \& Strynadka, N. C. (2006). New structural insights into the bacterial type III secretion system. Trends Biochem Sci 31, 223-230.

Yip, C. K., Kimbrough, T. G., Felise, H. B., Vuckovic, M., Thomas, N. A., Pfuetzner, R., Frey, E. A., Finlay, B. B., Miller, S. I. \& Strynadka, N. C. (2005). Structural characterization of the molecular platform for type III secretion system assembly. Nature 435, 702-707.

Edited by: T. Palmer 